\title{
Probing the Functional Equivalence of Otoferlin and Synaptotagmin 1 in Exocytosis
}

\author{
Ellen Reisinger, ${ }^{1}$ Chris Bresee, ${ }^{4 \star}$ Jakob Neef, ${ }^{2 \star}$ Ramya Nair, ${ }^{5 \star}$ Kirsten Reuter, ${ }^{1 \star}$ Anna Bulankina, ${ }^{2}$ Régis Nouvian, ${ }^{2}$ \\ Manuel Koch, ${ }^{2}$ Johanna Bückers, ${ }^{7}$ Lars Kastrup, ${ }^{7}$ Isabelle Roux, ${ }^{8}$ Christine Petit, ${ }^{8}$ Stefan W. Hell, ${ }^{7,9}$ Nils Brose, ${ }^{6,9}$ \\ Jeong-Seop Rhee, ${ }^{5}$ Sebastian Kügler, ${ }^{3,9}$ John V. Brigande, ${ }^{4}$ and Tobias Moser ${ }^{2,9}$ \\ ${ }^{1}$ Molecular Biology of Cochlear Neurotransmission, Department of Otolaryngology, ${ }^{2}$ InnerEarLab, Department of Otolaryngology, and ${ }^{3}$ Department of Neurology, \\ University Medical Center Göttingen, 37099 Göttingen, Germany, ${ }^{4}$ Oregon Hearing Research Center, Oregon Health and Science University, Portland, Oregon 97239, \\ ${ }^{5}$ Neurophysiology Group, Department of Molecular Neurobiology, and 'Department of Molecular Neurobiology, Max Planck Institute of Experimental Medicine, \\ 37075 Göttingen, Germany, ${ }^{7}$ Department of NanoBiophotonics, Max Planck Institute for Biophysical Chemistry, 37077 Göttingen, Germany, ${ }^{8}$ Inserm, Unité Mixte \\ de Recherche en Santé 587, Unite de Genetique des Deficits Sensoriels, College de France, Institut Pasteur, 75015 Paris, France, and ${ }^{9}$ Center for Molecular Physiology \\ of the Brain, University of Göttingen, 37073 Göttingen, Germany
}

Cochlear inner hair cells (IHCs) use $\mathrm{Ca}^{2+}$-dependent exocytosis of glutamate to signal sound information. Otoferlin (Otof), a $\mathrm{C}_{2}$ domain protein essential for IHC exocytosis and hearing, may serve as a $\mathrm{Ca}^{2+}$ sensor in vesicle fusion in IHCs that seem to lack the classical neuronal $\mathrm{Ca}^{2+}$ sensors synaptotagmin 1 (Syt1) and Syt2. Support for the $\mathrm{Ca}^{2+}$ sensor of fusion hypothesis for otoferlin function comes from biochemical experiments, but additional roles in late exocytosis upstream of fusion have been indicated by physiological studies. Here, we tested the functional equivalence of otoferlin and Syt1 in three neurosecretory model systems: auditory IHCs, adrenal chromaffin cells, and hippocampal neurons. Long-term and short-term ectopic expression of Syt1 in IHCs of Otof ${ }^{-/}$mice by viral gene transfer in the embryonic inner ear and organotypic culture failed to rescue their $\mathrm{Ca}^{2+}$ influx-triggered exocytosis. Conversely, virally mediated overexpression of otoferlin did not restore phasic exocytosis in Syt1-deficient chromaffin cells or neurons but enhanced asynchronous release in the latter. We further tested exocytosis in Otof ${ }^{-/-}$hippocampal neurons and in Syt1 ${ }^{-1-}$ IHCs but found no deficits in vesicle fusion. Expression analysis of different synaptotagmin isoforms indicated that Syt 1 and Syt 2 are absent from mature IHCs. Our data argue against a simple functional equivalence of the two $\mathrm{C}_{2}$ domain proteins in exocytosis of IHC ribbon synapses, chromaffin cells, and hippocampal synapses.

\section{Introduction}

Hearing relies on temporally precise and reliable $\mathrm{Ca}^{2+}$ influxdriven exocytosis of synaptic vesicles at the ribbon-type active zones of hair cells. The multi- $\mathrm{C}_{2}$ domain protein otoferlin (Otof)

Received Nov. 15, 2010; revised Jan. 6, 2011; accepted Jan. 24, 2011.

T.M., E.R., J.V.B., and J.S.R. designed research; E.R., C.B., J.N., R. Nair, K.R., A.B., R. Nouvian, M.K., J.B., L.K., I.R., S.K., and J.V.B. performed research; T.M., E.R., J.V.B., and J.N. wrote the paper.

This work was supported by a Max Planck Society Tandem-Project grant (N.B., T.M.), German Federal Ministry of Education and Research Bernstein Center Grant 01 GQ0433 (T.M.), Center for Molecular Physiology of the Brain Grant FZT-103 (S.K., N.B., T.M.), and National Institute on Deafness and Other Communication Disorders Grants R01DC8595 (J.V.B.) and P30 DC005983. We thank R. Nehring and D. Reuter for production of the SLV and transduction of chromaffin cells and S. Anderson for help with the TIRFM. We thank Rebecca Medda and Mark Rutherford for advice regarding immunostaining for STED microscopy and Aaron B. Wong for help with image analysis. We thank Thomas C. Südhof for providing the Syt ${ }^{-1}$ mice and Peter Jonas for synaptotagmin primers and taqman probes. We thank Nadine Herrmann, Anja Galinski, and Nina Dankenbrink-Werder for expert technical assistance.

${ }^{*}$ C.B., J.N., R.Nair, and K.R. contributed equally to this work.

The authors declare no competing financial interests.

Correspondence should be addressed to the following: Tobias Moser, InnerEarLab, Department of Otolaryngology, Göttingen University Medical School, 37099 Göttingen, Germany, E-mail: tmoser@gwdg.de; John V. Brigande, Oregon Hearing Research Center, Oregon Health and Science University 3181 SW Sam Jackson Park Road, NRC04, Portland, OR 97239, E-mail: brigande@ohsu.edu; or Sebastian Kügler, Department of Neurology, University of Göttingen Medical Center, 37099 Göttingen, Germany, E-mail: sebastian.kuegler@med.uni-goettingen.de.

R. Nouvian's present address: Inserm, Unité 1051, Institut des Neurosciences de Montpellier, 34091 Montpellier, France.

I. Roux's present address: The Johns Hopkins School of Medicine, Department of Otolaryngology-Head and Neck Surgery, Baltimore, MD 21205.

DOI:10.1523/JNEUROSCI.5122-10.2011

Copyright $\odot 2011$ the authors $\quad 0270-6474 / 11 / 314886-10 \$ 15.00 / 0$ was shown to be essential in a late step of exocytosis, because absence of this protein nearly abolishes vesicle fusion despite the presence of docked vesicles (Roux et al., 2006). $\mathrm{C}_{2}$ domains mediate $\mathrm{Ca}^{2+}$-dependent and -independent phospholipid binding and are involved in cellular signaling, synaptic vesicle exocytosis, and plasma membrane repair (for review, see Rizo and Südhof, 1998; Cho and Stahelin, 2005; McNeil and Kirchhausen, 2005; Martens and McMahon, 2008). The presence of several $\mathrm{C}_{2}$ domains in otoferlin, some of which bind $\mathrm{Ca}^{2+}$, led to the hypothesis that otoferlin might be a $\mathrm{Ca}^{2+}$ sensor for fusion in inner hair cell (IHC) synapses (Roux et al., 2006; Ramakrishnan et al., 2009; Johnson and Chapman, 2010). This notion was supported by the finding that other potential $\mathrm{Ca}^{2+}$ sensors, such as synaptotagmin 1 (Syt1), Syt2, and Syt3 are missing from the hair cell synapse (Safieddine and Wenthold, 1999), a finding that is currently under debate (Beurg et al., 2010; Johnson et al., 2010). Otoferlin coprecipitates with the SNARE proteins SNAP-25 and syntaxin 1 (Roux et al., 2006), and individual otoferlin $\mathrm{C}_{2}$ domains stimulate the fusion of liposomes loaded with reconstituted SNAREs in the presence of $\mathrm{Ca}^{2+}$ (Johnson and Chapman, 2010). One obvious test of the $\mathrm{Ca}^{2+}$ sensor hypothesis of otoferlin function would be to probe the functional equivalence of both proteins in supporting vesicle fusion in otoferlin- and Syt1-dependent neurosecretory preparations. 
Otoferlin and Syt1 seem to serve multiple functions in regulating vesicle cycling. Studying a missense mutation of Otof originating from an ENU mutagenesis screen (Schwander et al., 2007), we recently implicated otoferlin in efficient vesicle replenishment at the inner hair cell active zone (Pangrsic et al., 2010). Given the multiple protein interactions of otoferlin (Heidrych et al., 2009; Roux et al., 2009), it might even serve additional, undiscovered functions at the presynaptic active zone. Several functions have also been assigned to Syt1: besides its role as $\mathrm{Ca}^{2+}$ sensor for vesicle fusion, it has been shown to function in vesicle replenishment (docking of large dense core vesicles: Chieregatti et al., 2002; de Wit et al., 2009), in positional priming of synaptic vesicles (Young and Neher, 2009), and in endocytosis (Nicholson-Tomishima and Ryan, 2004).

Although a more general comparison of the functional properties of otoferlin to the well characterized Syt 1 continues to be of interest, in this study, we focused on the question whether otoferlin and Syt 1 can functionally substitute for one another to preserve synchronous vesicle fusion. We tested for such cross-rescue in Syt1-dependent and otoferlin-dependent neurosecretory preparations. Our results demonstrate that neither ectopic expression of otoferlin in Syt1-deficient chromaffin cells and hippocampal neurons nor ectopic expression of Syt 1 in otoferlin-deficient cochlear IHCs restores synchronous exocytosis, arguing against a simple functional equivalence of these two proteins. Furthermore, otoferlin deletion did not affect transmitter release at hippocampal synapses and vesicle fusion appeared unchanged in Syt1-deficient IHCs.

\section{Materials and Methods}

Mouse mutagenesis. To generate Otof ${ }^{-/-}$mice, a targeting vector was constructed in which exons 14 and 15 of the wild-type Otof gene were replaced by a loxP flanked neomycin selection cassette by subcloning into the NdeI and NsiI restriction sites located in the respective intron regions. The targeting construct consisted of 2.7- and 5.3-kb-long linkers for homologous recombination upstream and downstream of the loxP flanked neomycin cassette. A thymidine kinase cassette for negative selection was added after the 5.3-kb-long arm. This targeting construct was electroporated into 129ola embryonic stem cells, and cell colonies were picked after selection with G418 and ganciclovir. Homologous recombination was tested by Southern blot analysis after BclI digest using a BclI site upstream exon 11 and a newly introduced BclI site next to NdeI. From 96 cell clones analyzed, six were found to show the Southern blot pattern expected for homologous recombination ( $7.5 \mathrm{~kb}$ band). Two of these clones were injected into mouse blastocysts, which both led to germ-line transmission in male chimeric mice. Heterozygous offspring from the chimeras were bred with a cre-recombinase-expressing mouse line to excise the neomycin cassette. Excision of exons 14 and 15 leads to a frame shift and premature stop during translation of the Otof mRNA. In immunostainings of the cochlea, otoferlin protein was not detectable in Otof ${ }^{-/-}$mice with antibodies targeting $\mathrm{N}$ or $\mathrm{C}$ terminus of the protein (Pangrsic et al., 2010).

Virus transduction of IHCs. Adeno-assosicated virus (AAV) containing inverted terminal repeats of serotype 2 and capsid proteins of serotypes 1 and 2 (AAV-1/2) was prepared as described (Kugler et al., 2007).

For in vitro transduction, coverslips were coated with Celltak (BD Biosciences) and air dried. Organs of Corti (OCs) of postnatal day 0 (P0) mice $\left(S y t 1^{-1-}\right.$ and control littermates) or P8-P9 mice (Otof ${ }^{-1-}$ and wild-type controls) were dissected in sterile balanced HBSS containing $250 \mathrm{ng} / \mathrm{ml}$ fungizone and $10 \mu \mathrm{g} / \mathrm{ml}$ penicillin. Dissected organs of Corti were placed in DMEM/F-12 with 5\% FBS and attached to the coverslips by gentle pressure. After $1 \mathrm{~d}$ in vitro (DIV), organotypic cultures were washed once in PBS, and $300 \mu \mathrm{l}$ of DMEM/F-12 (without FBS), containing $8 \times 10^{8}$ particles of AAV-1/2, were applied. After $24 \mathrm{~h}, 300 \mu \mathrm{l}$ of DMEM/F-12 with 5\% FBS were added to the cultures, and 1-2 d later, the medium was replaced with $1 \mathrm{ml}$ of DMEM/F-12 with 5\% FBS.
For in vivo transduction, viral inoculum $\left(\sim 250 \mathrm{nl}, 4 \times 10^{8}\right.$ particles/ $\mu \mathrm{l})$ was microinjected through the uterus into the mouse otocyst at embryonic day $11.5-12.5$ as described previously (Gubbels et al., 2008; Brigande et al., 2009). Only the left otocyst of each embryo was injected, and the uninjected contralateral ear served as an internal control.

Immunohistochemistry in organs of Corti, confocal microscopy, and image analysis. For cochlear cryosections, temporal bones were fixed for $1 \mathrm{~h}$ in $4 \%$ formaldehyde, decalcified (only at P19) for $48 \mathrm{~h}$ in $0.12 \mathrm{~mm}$ EDTA in PBS, incubated in $25 \%$ sucrose overnight at $4^{\circ} \mathrm{C}$, and embedded in TissueTek (Shandon Cryomatrix, Thermo Fisher Scientific). Sixteen micrometer cryosections or whole-mount organs of Corti were immunostained as described (Khimich et al., 2005) using the following antibodies: monoclonal anti-otoferlin (diluted 1:500; Abcam); rabbit anti-VGlut3 (1:500), monoclonal anti-Syt1 (clone 41.1; 1:1000), rabbit or monoclonal anti-calbindin (1:2000) (all from Synaptic Systems); mouse monoclonal znp-1 (anti-Syt2) (1:1000; Zebrafish International Resource Center); and secondary Alexa Fluor 488-labeled and Alexa Fluor 568-labeled antibodies (1:200; Invitrogen).

Confocal images were acquired using a laser scanning confocal microscope (Leica TCS SP2 or SP5; Leica MicrosystemsCMS) with $488 \mathrm{~nm}$ (argon) and $561 \mathrm{~nm}$ (helium-neon) lasers for excitation and $63 \times$ oilimmersion objectives. Optical sections were acquired at steps of $0.7 \mu \mathrm{m}$, and $z$-stacks were maximum intensity projected in NIH ImageJ.

High-resolution stimulated emission depletion microscopy. Immunostaining of whole-mount apical organ of Corti turns was performed as for confocal microscopy with some variations. Excess primary antibody was removed by washing $10 \mathrm{~min}$ in $20 \mathrm{~mm}$ phosphate buffer, $0.3 \%$ Triton $\mathrm{X}-100$, and $0.45 \mathrm{M} \mathrm{NaCl}$, followed by three, 10 min washes in $2.5 \%$ goat serum in PBS. KK114-coupled sheep anti-mouse and Atto594-coupled goat anti-rabbit antibodies were applied 1:100 in 2.5\% goat serum in PBS for $1 \mathrm{~h}$ at room temperature. Organs of Corti were washed three times for $30-40 \mathrm{~min}$ in 10\% goat serum in PBS and embedded in $2^{\prime} 2$ thiodiethanol as described (Staudt et al., 2007). Imaging was performed at $1 \mathrm{~ms}$ dwell time (accommodating 1000 laser pulses) with $\sim 0.5 \mu \mathrm{W}$ excitation at wavelengths 570 and $650 \mathrm{~nm}$ and with $\sim 1.5 \mathrm{~mW}$ stimulated emission depletion (STED) power at wavelengths 720 and $755 \mathrm{~nm}$ in the aperture of the objective. Fluorescence signals were detected at 620 and $670 \mathrm{~nm}$, respectively. Images were background subtracted as estimated in a region of interest nearby the IHC and deconvoluted using the Richardson-Lucy algorithm with 25 iterations and a regularization parameter of $10^{-10}$.

Auditory brainstem responses and distortion product otoacoustic emissions. Two separate sets of auditory brainstem response (ABR) data were recorded in Portland and Göttingen using slightly different equipment. In both cases, mice were anesthetized intraperitoneally with a ketamine/ xylazine solution in $0.9 \%$ saline, needle electrodes were placed in the skin of vertex and subaurically, and hearing threshold was determined with 10 $\mathrm{dB}$ precision as the lowest stimulus intensity that evoked a reproducible response waveform in both traces by visual inspection.

For dataset 1 (Portland), a speaker was placed in the ear canal and a sequential stimulus consisting of pure tones of 4 to $32 \mathrm{kHz}$ was executed, with each tone burst presented at 10 different intensities for $2 \mathrm{~ms}$ each. ABRs were recorded as $12 \mathrm{~ms}$ acquisitions. Dataset 2 (Göttingen) was recorded as described by Neef et al. (2009). In brief, tone bursts (4-32 $\mathrm{kHz}, 10 \mathrm{~ms}$ plateau, $1 \mathrm{~ms} \cos ^{2}$ rise/fall) or clicks of $0.03 \mathrm{~ms}$ were generated using Tucker-Davis Technologies hardware presented at $20 \mathrm{~Hz}$ in the free field ipsilaterally using a JBL 2402 speaker (JBL GmbH and Co.). The difference potential between vertex and mastoid subdermal needles was amplified (50,000 times), filtered (low pass, $4 \mathrm{kHz}$; high pass, 100 $\mathrm{Hz}$ ), and sampled at a rate of $50 \mathrm{kHz}$ for $20 \mathrm{~ms}, 2 \times 2000$ times to obtain two mean ABRs for each sound intensity. For ABR comparisons of injected and non-injected ears of wild-type mice, the other ear was occluded with electrode gel and measured the other day in random order (gel was gone by then). For distortion product otoacoustic emissions (DPOAEs), a 24-bit sound card and the ED1/EC1 speaker system (Tucker-Davis Technologies) were used to generate two primary tones (ratio f2/f1: 1.2). Primary tones were coupled into the ear canal by a custom-made probe containing an MKE-2 microphone (Sennheiser) and adjusted to an intensity of $60 \mathrm{~dB}$ sound pressure level (SPL) at the position of the ear drum as mimicked in a mouse ear coupler. The 
microphone signal was amplified (DMP3; Midiman) and analyzed by fast Fourier transformation.

Patch clamp of IHCs. All cell physiology experiments (IHCs, chromaffin cells, and neurons) were performed at room temperature $\left(20-25^{\circ} \mathrm{C}\right)$. IHCs from cultured organs of Corti from neonatal mice (see below) or from acute explants of the apical coil of the organ of Corti from 4-week-old mice were whole-cell patch clamped essentially as described previously (Moser and Beutner, 2000). The pipette solution contained the following (in $\mathrm{mm}$ ): 130 Cs-gluconate, 10 tetraethylammonium-Cl (TEA-Cl), 10 4-aminopyridine (4-AP), 10 Cs-HEPES, 1 $\mathrm{MgCl}_{2}$, and amphotericin B $(300 \mu \mathrm{g} / \mathrm{ml}$, for perforated patch; Calbiochem) or $2 \mathrm{~mm} \mathrm{Mg-}$ ATP and $0.3 \mathrm{~mm} \mathrm{Na-GTP} \mathrm{(for} \mathrm{ruptured} \mathrm{patch).}$ The extracellular solution contained the following (in $\mathrm{mm}$ ): $107 \mathrm{NaCl}, 35 \mathrm{TEA}-\mathrm{Cl}, 10$ HEPES, 5 4-AP, $2.8 \mathrm{KCl}, 2 \mathrm{CaCl}_{2}, 1 \mathrm{MgCl}_{2}, 1$ $\mathrm{CsCl}_{2}$, and 11.2 glucose for acutely explanted organs of Corti [for cultured OCs: $105 \mathrm{~mm}$ $\mathrm{NaCl}, 10 \mathrm{mM} \mathrm{CaCl}_{2}$ (to enhance the low $\mathrm{Ca}^{2+}$ currents $\left[I_{\mathrm{Ca}}\right]$ in cultured IHCs), and $100 \mathrm{~nm}$ apamin], 290-310 mOsm/L, pH 7.2. EPC-9 amplifiers (Heka) controlled by Pulse software (Heka) were used for measurements. Currents were low-pass filtered at 2 or $4 \mathrm{kHz}$, sampled at $10 \mathrm{kHz}$, and $\mathrm{P} / 10$ leak corrected. IHCs were discarded when leak currents exceeded $-50 \mathrm{pA}$ at $-84 \mathrm{mV}$. Capacitance measurements were performed as described (Neef et al., 2009) using the Lindau-Neher technique implemented as the "sine $+\mathrm{dc}$ " mode of the "software lockin" extension of Pulse software. A $1 \mathrm{kHz}, 70$ $\mathrm{mV}$ peak-to-peak sinusoid stimulus was applied about a direct current holding potential of $-84 \mathrm{mV}$.

Single-cell real-time PCR. Real-time PCR for the detection of 14 Syt isoforms was performed as described (Kerr et al., 2008). Briefly, a patch pipette, filled as described above for ruptured patch, was approached with positive pressure toward an individual rat IHC and used to aspirate its cytoplasm. The contents of the pipette were expelled into a solution for reverse transcription of mRNA. The cDNA was ethanol precipitated, and amplicons were preamplified with 15 cycles of a multiplex PCR before the real-time PCR. Samples from each cell were split to perform TaqMan real-time PCR for each Syt isoform in a separate reaction tube (sequences of oligos and TaqMan probes as by Kerr et al., 2008). For negative controls, bath solution in close proximity to IHCs was aspirated into patch pipettes before and after IHC harvesting (bath controls 1 and 2), and reverse transcriptase was omitted from one cell (-RT control). cDNA from total organ of Corti was used as a template to control amplification of the individual TaqMan assays (positive control).

Transfection, patch-clamp, photolysis of caged $\mathrm{Ca}^{2+}$ and measurements of $\left[\mathrm{Ca}^{2+}\right]$, total internal reflection microscopy of chromaffin cells. Bovine and mouse adrenal chromaffin cells were prepared as described (Smith et al., 1998; Sørensen et al., 2003). A semliki forest virus (SFV) was used to transfect chromaffin

F
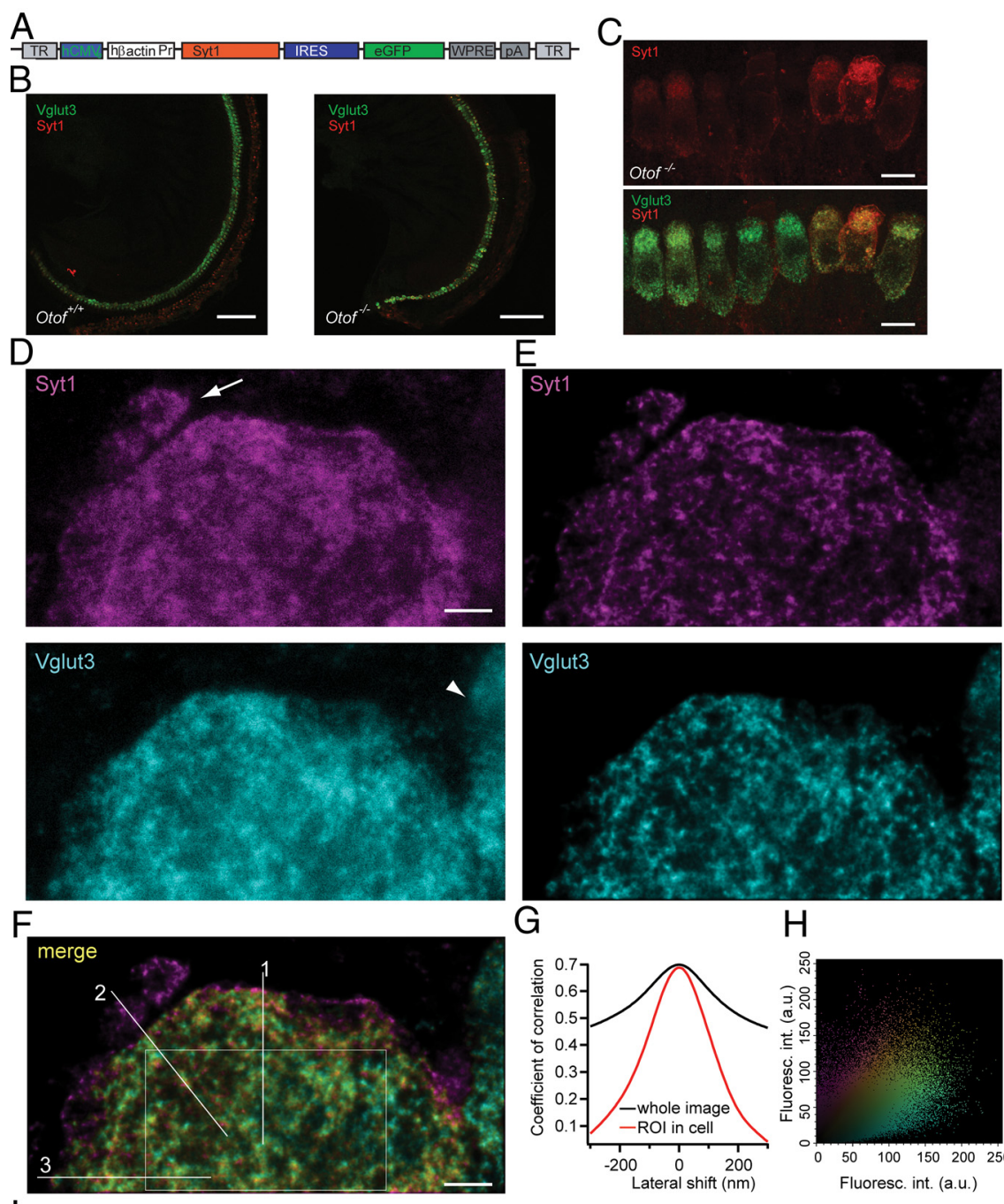
G
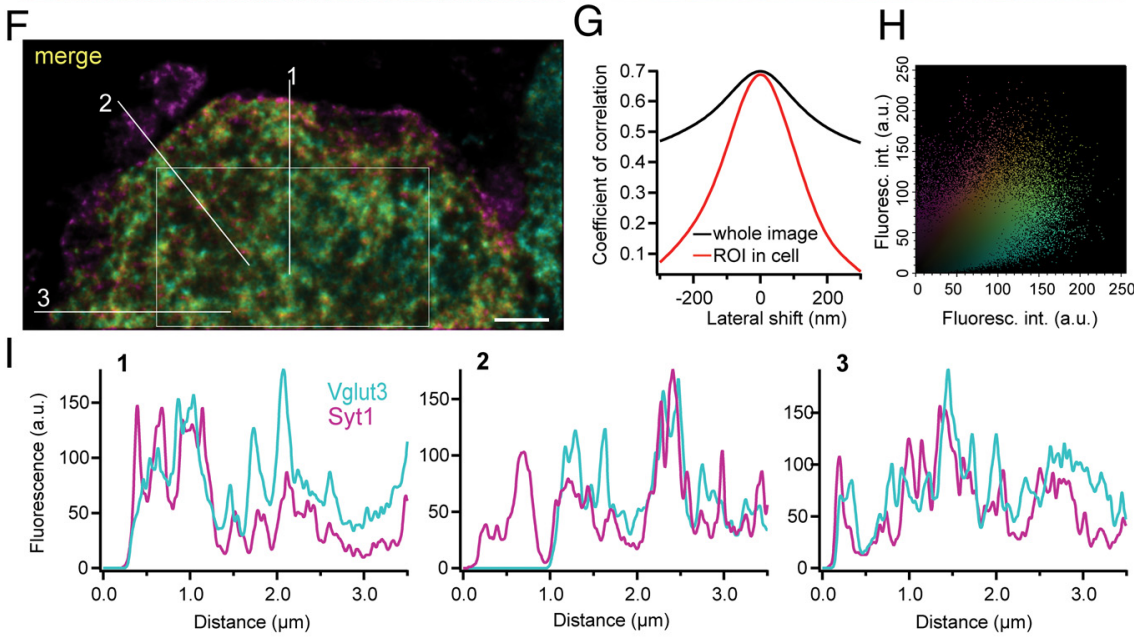

Figure 1. Syt1 is properly targeted in IHCs after AAV-mediated gene transfer. A, Layout of the AAV-1/2 Syt1-IRES-eGFP construct. TR, Terminal repeats; hCMVe, human cytomegalovirus enhancer; Pr, promoter; IRES, internal ribosomal entry site; eGFP, enhanced green fluorescent protein; WPRE, woodchuck hepatitis virus posttranscriptional control element; pA, polyadenylation signal. $\boldsymbol{B}$, Projections of low-resolution confocal sections of wild-type and $\mathrm{Otof}^{-1-}$ organs of Corti after transuterine injection of the embryonic otocyst using AAV-1/2 Syt1-IRES- eGFP, immunolabeled for Syt1 (red) and Vglut3 (green). Scale bar, $100 \mu \mathrm{m}$. C, Projections of confocal sections of immunolabeled organs of Corti of Otof ${ }^{-/} 7 \mathrm{~d}$ after viral Syt1 transduction. Scale bar, $10 \mu \mathrm{m}$. D, Highresolution two-color STED imaging of the basal pole of one virus-transfected IHC immunolabeled for Syt1 and Vglut3. Scale bar, $1 \mu \mathrm{m}$. Image resolution is $50 \mathrm{~nm}$ in lateral and $800 \mathrm{~nm}$ in axial direction, and pictures are background subtracted. Note the afferent bouton stained for endogenous Syt1 only (arrow) and the adjacent nontransfected IHC with only Vglut3 labeling (arrowhead). $\boldsymbol{E}$, The pictures in $\boldsymbol{D}$ were deconvoluted using the Richardson-Lucy algorithm (Holmes and Liu, 1989) with 25 iterations and a regularization parameter of $10^{-10} . \boldsymbol{F}_{\text {, }}$ Merge of the pictures from $\boldsymbol{E}$. Sole Syt1 staining is indicated in magenta, and Vglut3 staining is in cyan. The color spectrum indicates the weighted contribution of both channels, with yellow indicating equal fluorescence intensity in both channels. G, The Pearson's correlation coefficient is reduced by a lateral shift of the images from both channels, less severely for the whole image (black line), and more obviously for the region of interest (ROI) as indicated in $\boldsymbol{F}$ (red line). $\boldsymbol{H}$, Fluorescence intensity (Fluoresc. int.) for Syt1 in one pixel of $\boldsymbol{F}$ is plotted against the fluorescence intensity derived from Vglut3 immunofluorescence in the same pixel. Color coding as in $\boldsymbol{F}$. a.u., Arbitrary units. $\boldsymbol{I}$, Fluorescence intensity histogram in both color channels along the three lines sketched in $\boldsymbol{F}$.

cells with cDNA encoding for otoferlin with C-terminal fusion to enhanced green fluorescent protein (Otof-eGFP). The SFV was produced as described (Berglund et al., 1993; Smerdou and Liljeström, 1999). Cells were transfected $1 \mathrm{~d}$ after plating and used for analysis $24 \mathrm{~h}$ later. Cells 
Table 1. Percentage of inner and outer hair cells in the 0 tof $^{-/-}$and wild-type cochlea transfected with AAV-1/2 vector (means \pm SD)

\begin{tabular}{lllll}
\hline Vector/host strain & $n$ & Base & Midbase & Apex \\
\hline Inner hair cells & & & & \\
$\quad$ Syt1- eGFP/Otof & 7 & $20.3 \pm 25.1^{c, d}$ & $67.4 \pm 27.0^{d, e}$ & $71.1 \pm 24.3^{b, c}$ \\
$\quad$ eGFP/WT & 6 & $20.7 \pm 16.3^{h, i}$ & $82.8 \pm 21.2^{i, j}$ & $67.5 \pm 19.4^{h}$ \\
$\quad$ Syt1- eGFP/WT & 4 & $56.7 \pm 24.0$ & $75.9 \pm 17.0$ & $62.1 \pm 15.5$ \\
Outer hair cells & & & & \\
$\quad$ Syt1-eGFP/0tof & 7 & $4.57 \pm 6.9^{a}$ & $14.2 \pm 14.0^{e, k}$ & $35.1 \pm 23.0^{a, b}$ \\
$\quad$ eGFP/WT & 6 & $9.8 \pm 7.7^{f, g}$ & $36.0 \pm 19.3^{f, j, k}$ & $41.0 \pm 20.0^{g}$ \\
Syt1- eGFP/WT & 4 & $27.1 \pm 17.0$ & $30.3 \pm 24.7$ & $42.9 \pm 56.5$ \\
\hline
\end{tabular}

WT, Wild type. ${ }^{a} p=0.02,{ }^{b} p=0.009,{ }^{c} p=0.006,{ }^{d} p=0.003,{ }^{e} p=0.001,{ }^{f} p=0.03,{ }^{g} p=0.02,{ }^{h} p=0.005,{ }^{i} p=$ $0.003,{ }^{j} p=0.002$, by repeated measures ANOVA; ${ }^{k} p=0.04$, by paired samples $t$ test.
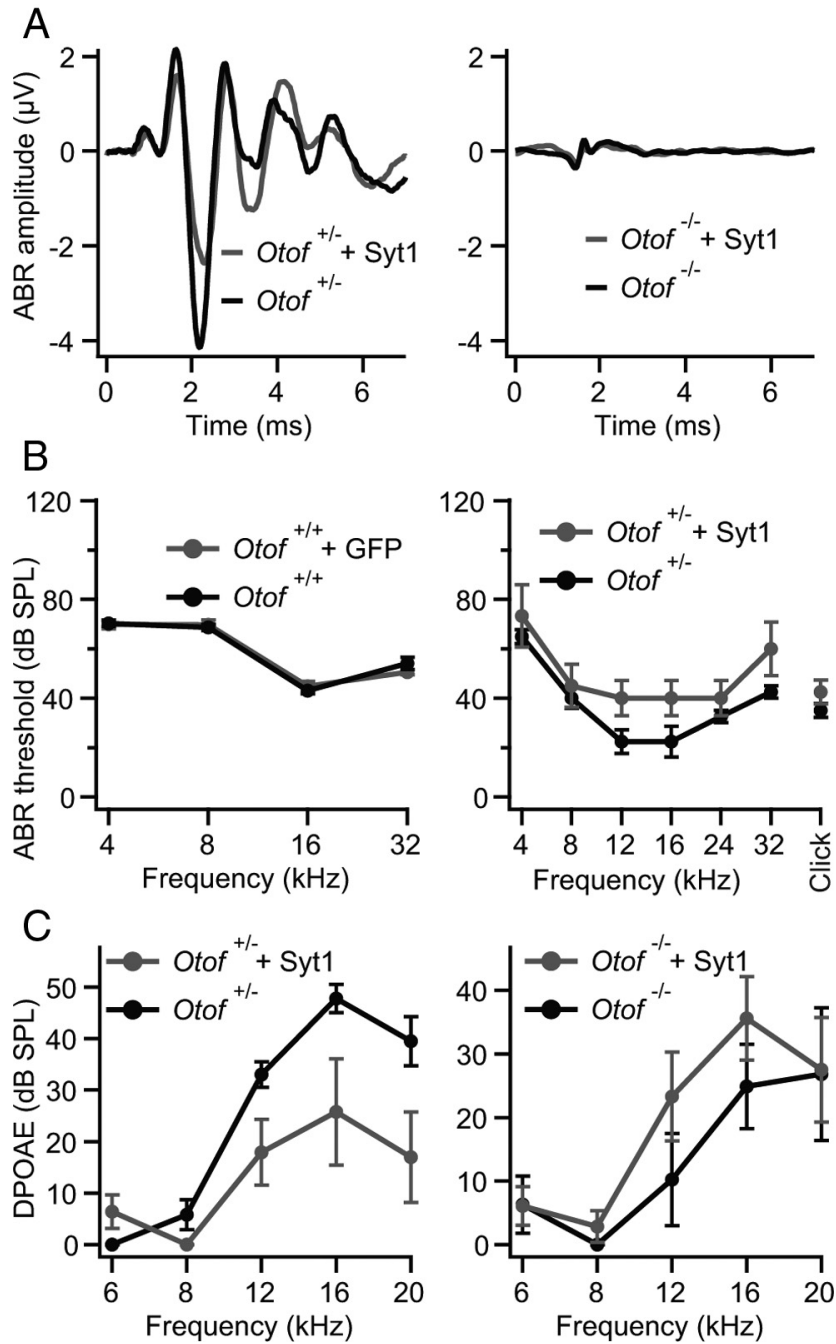

Figure 2. Syt1 does not restore hearing of Otof ${ }^{-/-}$mice. $A$, Auditory brainstem responses. Left, Mean ABR traces of non-injected (black) and Syt1-AAV-injected (gray) ears of Otof ${ }^{+/-}$animals $(n=$ 4) in response to $80 \mathrm{~dB}$ SPL click stimuli; right, mean $A B R$ traces of 0 tof $^{-{ }^{-}}$animals of which one ear was transfected with Syt1 (gray) and the non-injected contralateral ear served as control (black; $n=4$ ) in response to $100 \mathrm{~dB}$ SPL click stimuli. $\boldsymbol{B}$, Left, Mean ABR thresholds and SEM $(n=25)$ of non-injected and eGFP-transfected wild-type animals (C57BL/6J). Right, Mean ABR thresholds and SEM $(n=4)$ of non-injected and Syt1transfected $\mathrm{Otof}^{+/-}$mice. In both independent sets of virus transduction, no ABR response could be detected in non-injected and in Syt1-transfected Otof ${ }^{-1-}$ mice for SPLS up to $120 \mathrm{~dB}(n=29)$. C, Outer hair cell function was confirmed by DPOAEs for $\mathrm{Otof}^{+/-}$ and $\mathrm{Otof}^{-/-}$mice (same animals as in the right of $\boldsymbol{B}$ ). Although in $\mathrm{Otof}^{+/-}$mice the DPOAEs were slightly worse after virus injection (left) and might be a reason for the slightly elevated ABR thresholds in B, DPOAEs in $\mathrm{Otof}^{-1-}$ seem not to be affected by virus transduction (right).
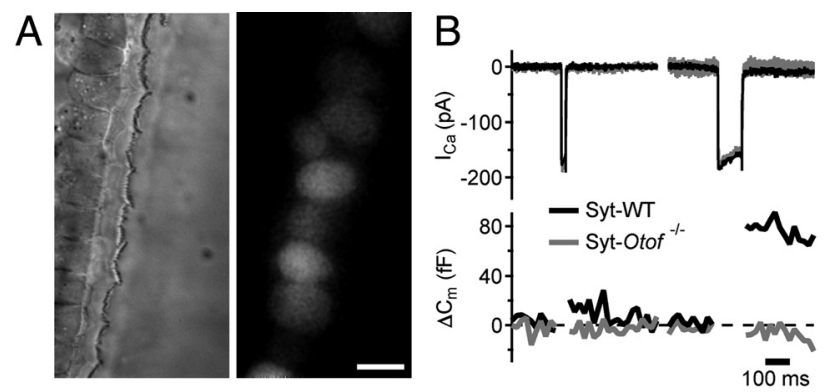

$\mathrm{C}$

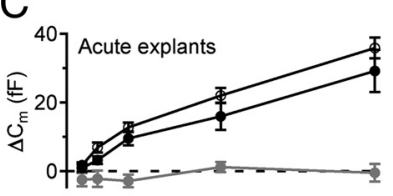

D
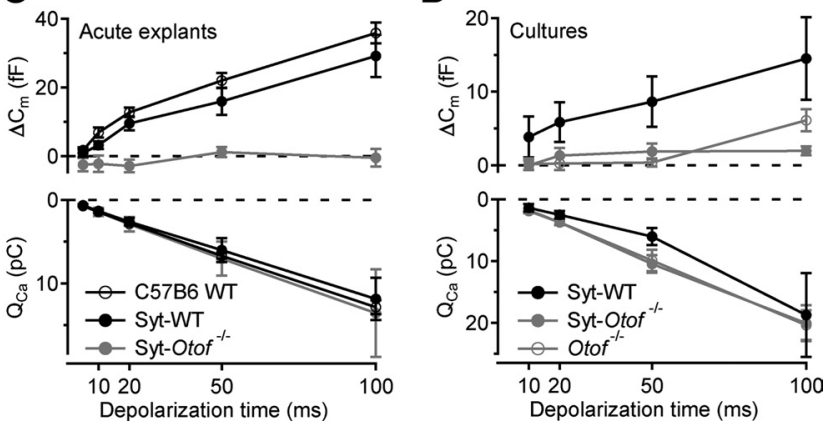

Figure 3. Syt1 overexpression by in vivo and in vitro AAV transduction do not restore exocytosis in IHCs of 0 tof ${ }^{-1-}$ mice. $A$, Representative differential interference contrast (left) and fluorescence (right) images of P35 IHCs after transuterine transduction of the embryonic otocyst using AAV-1/2 Syt1-IRES- eGFP: preserved stereocilia and high transduction rate (chain of eGFP-positive IHC somata). Scale bar, $5 \mu \mathrm{m}$. $\boldsymbol{B}$, Synaptic function in Syt1 misexpressing IHCs in acutely isolated $\mathrm{P} 35$ organs of Corti. Representative $I_{\mathrm{Ca}}$ currents (top) and $\Delta C_{\mathrm{m}}$ in response to a $20 \mathrm{~ms}$ (left) and $100 \mathrm{~ms}$ (right) depolarization to $-14 \mathrm{mV}$, recorded in perforated-patch configuration from IHCs of wild-type (WT; black, CD1) and Otof ${ }^{-/-}$(gray, mixed background) mice that had been transfected in utero. $C$, Mean $\Delta C_{m}$ (top) and $Q_{C a}$ (bottom) responses of nontransfected 4-week-old C57BL/6J IHCs (open circles; $n=12$ ), AAV-1/2 Syt1-IRES-eGFPtransfected CD1 IHCs (filled black circles; $n=9$ ), and AAV-1/2 Syt1-IRES-eGFP-transfected Otof ${ }^{-1-}$ IHCS (filled gray circles; $n=6$ ); experiments as in $\boldsymbol{B}$. D. Mean $\Delta C_{\mathrm{m}}$ (top) and $Q_{C_{a}}$ (bottom) responses of IHCs from in vitro AAV-1/2 Syt1-IRES-eGFP-transfected cultures of $\mathrm{C} 7 \mathrm{BL} / 6 \mathrm{~J}$ and 0 tof $^{-1-}$ organs of Corti; experiments as in $\boldsymbol{B}$ but ruptured patch in the presence of $10 \mathrm{~mm}\left[\mathrm{Ca}^{2+}\right]_{\mathrm{e}}$

were chosen for physiological analysis by their GFP fluorescence (preferring intermediate fluorescence). A Nikon TE-2000 microscope equipped with the NIKON TIRF-condensor and a 1.45 numerical aperture objective was combined with a Picarro Cyan laser $(488 \mathrm{~nm}, 20 \mathrm{~mW})$ and an Andor iXon 887 BI CCD for "through the lens total internal reflection microscopy (TIRFM)." The laser beam was focused onto the back focal plane of the objective and moved off-axis to obtain total reflection at the glass-water interface. The resulting evanescent field allowed for a selective excitation of near-plasma-membrane fluorescence. One pixel of the CCD represented $107 \mathrm{~nm}$ in the image plane. Images were acquired at $100 \mathrm{~Hz}$ without stimulation of the chromaffin cells.

Whole-cell recordings were performed with $5-6 \mathrm{M} \Omega$ pipettes using an EPC-9 patch-clamp amplifier together with Pulse software. The pipette solution contained the following (in $\mathrm{mM}$ ): 100 Cs-glutamate, $8 \mathrm{NaCl}, 2$ Mg-ATP, $0.3 \mathrm{Na}_{2}$-GTP, 32 Cs-HEPES, 5 nitrophenyl-EGTA (NPEGTA), $4 \mathrm{CaCl}_{2}$, and 0.3 Furaptra, $\mathrm{pH}$ 7.2. The extracellular solution contained the following (in mM): $145 \mathrm{NaCl}, 2.8 \mathrm{KCl}, 2 \mathrm{CaCl}_{2}, 1 \mathrm{MgCl}_{2}, 10$ $\mathrm{Na}-\mathrm{HEPES}$, and 10 glucose, $\mathrm{pH}$ 7.4. Capacitance measurements were performed as described above for IHCs. To obtain stepwise increases in $\left[\mathrm{Ca}^{2+}\right]_{\mathrm{i}}$, short $(\sim 1.3 \mathrm{~ms})$ flashes of ultraviolet light from a xenon arc flash lamp (Rapp OptoElectronics) were applied to the NP-EGTAloaded chromaffin cells. $\left[\mathrm{Ca}^{2+}\right]_{i}$ was measured by dual-wavelength ratiometric fluorimetry with the indicator dye Furaptra. The dye was excited with light alternating between 350 and $380 \mathrm{~nm}$ using a monochromator-illumination-based system (T.I.L.L. Photonics), and the resulting fluorescent signal was measured using a photodiode. $\left[\mathrm{Ca}^{2+}\right]_{\mathrm{i}}$ was determined from the ratio $\mathrm{R}$ of the fluorescent signals at 
both wavelengths as described (Beutner et al., 2001). The isocoefficient (Zhou and Neher, 1993) was measured to be 0.1 .

Autaptic hippocampal neuron culture, electrophysiology, transduction, and morphology. Microisland cultures of hippocampal neurons from Syt1 $1^{-/-}$or Otof ${ }^{-/-}$mice and from wildtype controls were prepared as described (Jockusch et al., 2007) and recorded between 10 and 15 DIV. Syt1-deficient neurons were transfected $12 \mathrm{~h}$ before recordings using an SFV with Otof-eGFP (see chromaffin cells), eGFP, or Syt1 with N-terminal fusion to eGFP (eGFPSyt1). Neurons were whole-cell voltage clamped at $-70 \mathrm{mV}$ using an Axoclamp amplifier under the control of Clampex 10.1 software. All analyses were performed using Axograph 4.1 or Axograph X. EPSCs were evoked by depolarizing the cells to $0 \mathrm{mV}$. The extracellular saline solution contained the following (in mM): $140 \mathrm{NaCl}, 2.4 \mathrm{KCl}, 10 \mathrm{HEPES}$, 10 glucose, $4 \mathrm{CaCl}_{2}$, and $4 \mathrm{MgCl}_{2}$, pH $7.3(320$ $\mathrm{mOsm} / \mathrm{L}$ ). Pipette solutions contained the following (in $\mathrm{mm}$ ): $136 \mathrm{KCl}, 17.8$ HEPES, 1 EGTA, 4.6 $\mathrm{MgCl}_{2}$, 4 NaATP, $0.3 \mathrm{Na}_{2} \mathrm{GTP}, 15$ creatine phosphate, and $5 \mathrm{U} / \mathrm{ml}$ phosphocreatine kinase, pH 7.4 (315-320 mOsm/L). Neurons (cultured until 14 DIV) were fixed with $4 \%$ paraformaldehyde in PBS for $20 \mathrm{~min}$ and were stained with rabbit anti-Vglut1 (1:1000; Synaptic Systems) and mouse anti-otoferlin (1: 300 ; Abcam) and secondary antibodies as described for IHCs.

Data analysis. The data were analyzed using the IgorPro 6 software package (Wavemetrics) and Origin 6.0 (Microcal Software). Averaged data are expressed as mean \pm SEM. Significance was tested using the unpaired, two-tailed $t$ tests, unless stated otherwise. For Otof ${ }^{-/-}$hippocampal neurons, analysis was performed as described by Jockusch et al. (2007).

\section{Results}

Viral transduction of hair cells and targeting of misexpressed Syt 1 to synaptic vesicles

A prerequisite to study a potential functional equivalence of otoferlin and Syt1 in hair cells was to transfect Otof ${ }^{-1-}$ hair cells while maintaining cellular and/or cochlear integrity. Here, we established transduction by AAV of both postnatal IHCs in cultured organs of Corti (in vitro approach) and IHC progenitor cells after microinjection into the embryonic otocyst (in vivo approach: Gubbels et al., 2008; Brigande et al., 2009).

Numerous viral vectors (semliki forest virus SF40, lentivirus, and combinations of various AAV serotypes and promoters/ enhancers) collectively failed to transduce cultured IHCs. Finally, we found a chimeric $\mathrm{AAV}-1 / 2$ to efficiently transduce IHCs and outer hair cells (OHCs) both in vitro and in vivo when driving transgene expression by a cytomegalovirus (CMV) enhanced human $\beta$-actin promoter (Fig.
A
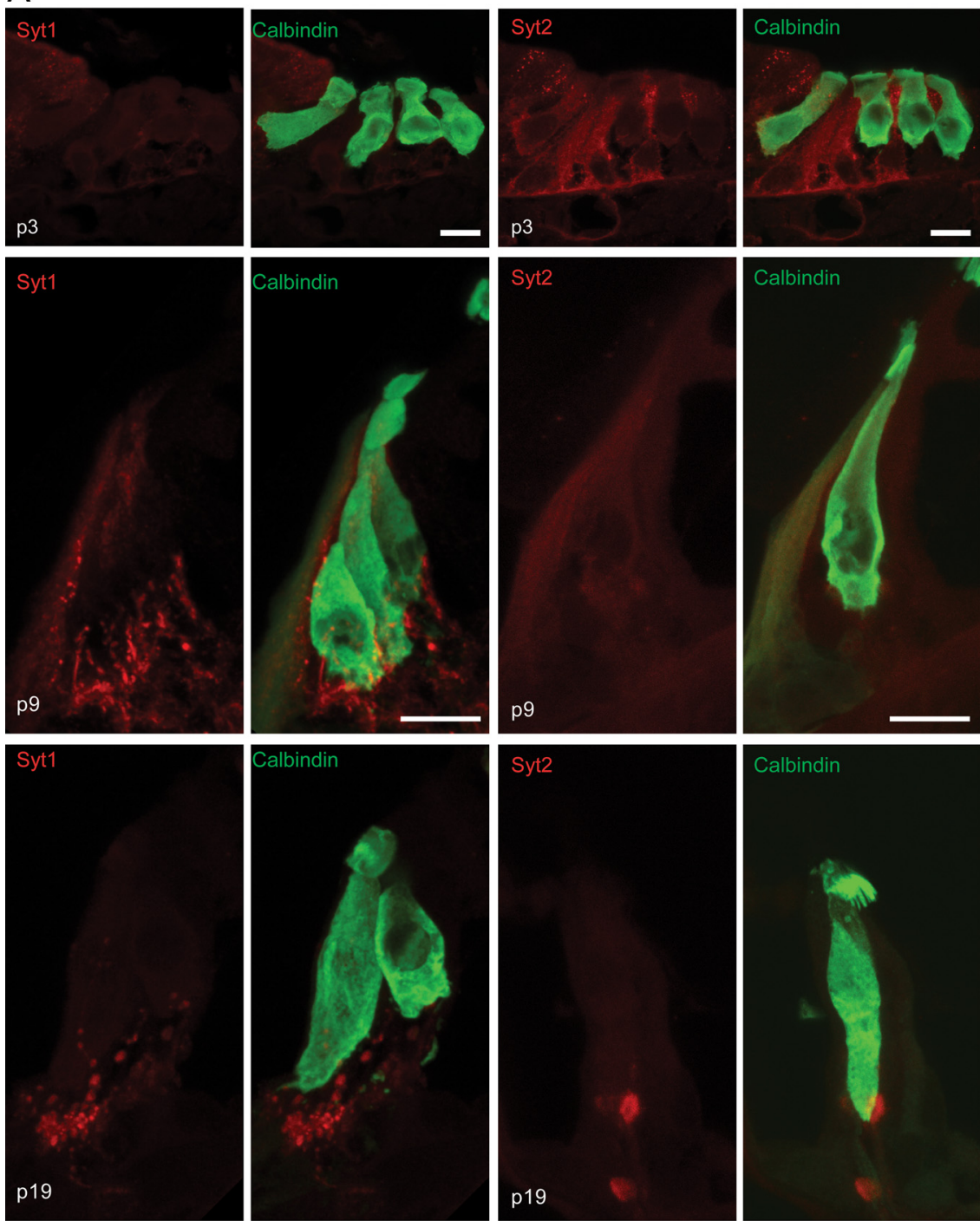

$\mathrm{B}$
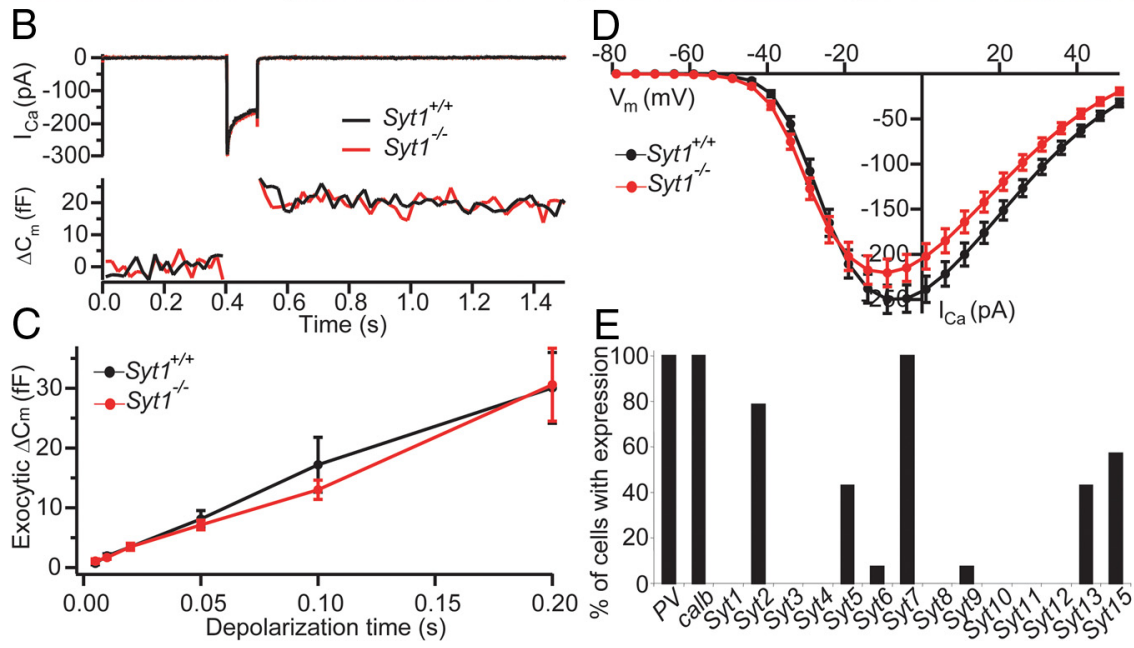

Figure 4. Syt expression analysis and presynaptic hair cell function in Syt $1^{-/-}$mice. $A$, Projection of confocal sections of cryosectioned wild-type organs of Corti from P3 (top), P9 (middle), and P19 (bottom) immunolabeled for calbindin (hair cell marker) and Syt1 (left) or Syt2 (right). Scale bar, $10 \mu \mathrm{m}$. B, Representative $I_{C_{a}}$ currents (top) and $\Delta C_{m}$ (bottom) in response to 100 ms depolarization to $-10 \mathrm{mV}$ recorded in perforated-patch configuration from IHCs in cultures of neonatal organs of Corti from a Syt $1^{-/-}$mouse and a Syt $1^{+/+}$littermate (cultured at PO, 6 DIV). C, Mean $\Delta C_{\mathrm{m}}$ as a function of stimulus duration for Syt $1^{+/+}$ $(n=22)$ and Syt $1^{-/-}(n=16)$ IHCs recorded as in B. D. Ca $^{2+}$ current-voltage relationship of Syt $1^{+/+}(n=23)$ and Syt $1^{-/-}$ $(n=16)$ IHCs. $E$, Expression of 14 Syt isoforms was tested by single-cell PCR in $14 \mathrm{IHCs}$ from P12 rats. 

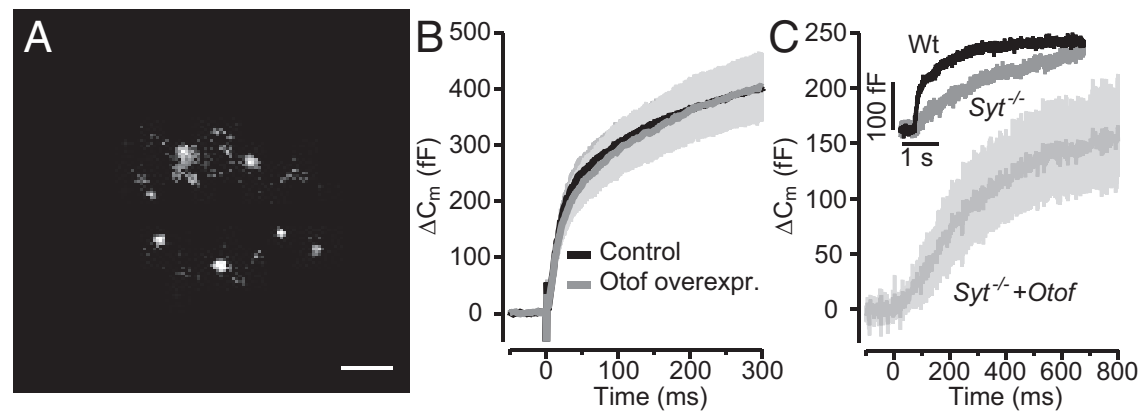

Figure 5. Overexpression of otoferlin in chromaffin cells does not change kinetics or amount of exocytosis and does not restore synchronous exocytosis in Syt1-deficient cells. A, TIRF image of the footprint of a chromaffin cell, which had been transfected with an otoferlin- eGFP fusion construct. Individual fluorescent spots most probably represent otoferlin-eGFP-tagged chromaffin granules. Scale bar, $1 \mu \mathrm{m}$. $B$, Average $\Delta C_{\mathrm{m}}$ in response to the first flash in control $(n=20$; black) and otoferlin-expressing $(n=$ 20; gray) bovine chromaffin cells. The first flash was delivered $120-180$ s after establishment of the whole-cell configuration. $C$ Exocytic responses of a wild-type (Wt) nontransfected mouse chromaffin cell (black) and mean response of five Syt1-deficient chromaffin cells that had been transfected to express the otoferlin- eGFP fusion construct: lack of the fast component of the exocytic burst. Inset, Representative exocytotic response from wild-type (black, postflash $\left[\mathrm{Ca}^{2+}\right]_{:}: 16.31 \mu \mathrm{M}$ ) and Syt1 knock-out (gray, postflash $\left[\mathrm{Ca}^{2+}\right]_{\mathrm{i}}: 15.5 \mu \mathrm{m}$ ).

$1 A)$. This virus contains inverted terminal repeats of serotype 2 and capsid proteins of serotypes 1 and 2. To identify Syt1transfected cells during patch-clamp experiments, we coexpressed eGFP via an internal ribosomal entry site (IRES) within the same viral construct (Fig. 1A). After in vitro application of this AAV-1/2 to cultured OCs explanted at P8, we found a substantial number of transfected IHCs, although the transduction rate varied significantly between OC cultures. For in vivo transduction, we microinjected this virus into the otocyst at embryonic days 11.5-12.5. The rate of IHC transduction varied as a function of tonotopy (highest in the low-frequency sensing cochlear apex and lowest in the high-frequency sensing base) and from experiment to experiment (Table 1), consistent with the findings in a proof of principle study of AAV-mediated gene transfer into the inner ear via injection into the developing otocyst (Bedrosian et al., 2006). In addition, we observed variable expression of the transgene in OHCs and spiral ganglion neurons (data not shown).

The localization of ectopically expressed Syt 1 in hair cells after otocyst injection was examined by colabeling of Syt1 and the vesicular protein Vglut3 and high-resolution imaging (confocal and STED microscopy). Confocal images (Fig. 1B) and STED images (Fig. $1 D$ with lateral and axial resolution of $\sim 50$ and 800 $\mathrm{nm}$ for both colors, respectively) showed a similar distribution pattern of Vglut3 and Syt1 in Syt1-transfected IHCs. Deconvolution of STED images revealed a more structured immunolabeling pattern for both Syt1 and Vglut3 (Fig. $1 E$ ). Note an efferent nerve ending with endogenous Syt1 immunoreactivity (Fig. $1 D$, arrow) and a part of a non-transfected cell stained for Vglut 3 only (arrowhead). Merging of the two color channels revealed a good correlation of the localization of the two antigens within the cytoplasm, whereas Syt1 labels the plasma membrane more intensely than Vglut3 (Fig. 1F). Furthermore, we probed the pixelwise correlation between the two fluorescence channels in deconvolved STED images of the basolateral end of a hair cell (Fig. 1G,H). The correlation coefficient within a region of interest (sketched in Fig. 1F) was 0.686, and it decreased during lateral shift arguing for a genuine colocalization of the two antigens (Fig. $1 G$ ). Fluorescence intensity histograms along three lines indicate a similar distribution of Syt1 and Vglut3 within the cell (Fig. 1I).
Functional impact of ectopic expression of Syt1 in IHCs of $\mathrm{Otof}^{-/-}$mice

We studied auditory function by recording ABRs in 4- to 5-week-old mice, whose left otocyst had been microinjected with the Syt1-encoding AAV at embryonic day 11.5-12.5 (Bedrosian et al., 2006; Gubbels et al., 2008). Wild-type ears injected with GFP or ears of normal hearing Otof ${ }^{+/-}$ animals injected with Syt1 served as controls. Ectopic expression of Syt1 in Otof ${ }^{-/}$IHCs did not result in any detectable ABR responses compared with the uninjected contralateral ears (Fig. 2A, right), even at $120 \mathrm{~dB}$ SPL, in two independent datasets, which were acquired by different experimenters. As reported previously (Bedrosian et al., 2006), ectopic expression of GFP in hair cells of wild-type mice did not interfere with their hearing (Fig. $2 B$, left). Injection of the Syt1-AAV caused an increase in hearing threshold in one set of experiments (data not shown), the reasons for which are currently unclear. Therefore, and because hearing thresholds in the uninjected wild-type ears were relatively high (Fig. $2 \mathrm{~B}$, left), we performed the second set of experiments in which we also recorded otoacoustic emissions to test for potential changes in OHC-mediated cochlear amplification (Fig. $2 A-C$ ). For this, we cross-bred Otof ${ }^{-1-}$ with Otof ${ }^{+1-}$ mice and injected the same Syt1 encoding AAV into the otocysts of all pups, such that we could test hearing and outer hair cell function in Otof ${ }^{-/-}$and in hearing $\left(\mathrm{Otof}^{+/-}\right)$animals that had been injected within the same experiment. Otoacoustic emissions were detectable in both injected and uninjected ears of both Otof ${ }^{+/-}$and Otof ${ }^{-1-}$ mice (Fig. 2C), and hearing thresholds were not significantly different between injected and uninjected ears of Otof ${ }^{+/}$mice ( $p>0.05$ for all frequencies) (Fig. $2 B$, right). There was a tendency toward elevated thresholds in the midfrequency range for which we found low IHC transduction. Low-frequency hearing mediated by the cochlear apex was completely unaltered, arguing against adverse effects of AAV injection on cochlear function in this second set of experiments, in which we achieved high transduction rates of apical IHCs $(\sim 60 \%)$. Therefore, despite proper protein targeting, ectopic expression of Syt1 in IHCs does not restore hearing in Otof ${ }^{-1-}$ mice, suggesting a continued failure of synaptic transmission in Syt1expressing Otof ${ }^{-/-}$IHCs.

Differential interference contrast microscopy of IHC and OHC hair bundles and cell bodies further indicated that IHCs were intact in the transfected cochleae (Fig. 3A). Next, we studied the presynaptic function of Syt1-transfected apical IHCs of 4-week-old Otof ${ }^{-1-}$ and Otof ${ }^{+/+}$mice by patch-clamp recordings of $\mathrm{Ca}^{2+}$ current and membrane capacitance increments $\left(\Delta C_{\mathrm{m}}\right)$ (Fig. 3B,C). Ectopic expression of Syt1 in Otof ${ }^{+/+}$IHCs did not interfere with $\mathrm{Ca}^{2+}$ currents and $\Delta C_{\mathrm{m}}$ compared with nontransfected IHCs (Fig. 3C). Still, Syt1-expressing Otof ${ }^{-1-}$ IHCs did not show any significant $\Delta C_{\mathrm{m}}$ in response to sizeable $\mathrm{Ca}^{2+}$ currents (Fig. 3 B,C). Thus, exocytosis of mature IHCs in Otof ${ }^{-1-}$ mice cannot be restored by ectopic expression of Syt 1 in IHCs by in utero gene transfer to hair cell progenitors in the embryonic inner ear.

As a complementary approach, we transfected P8-P9 Otof ${ }^{-/-}$ and $\mathrm{Otof}^{+/+}$IHCs in organotypic culture using the same virus and 
A

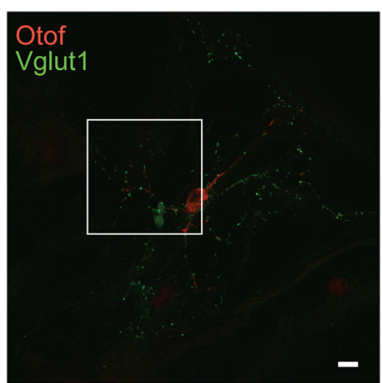

B

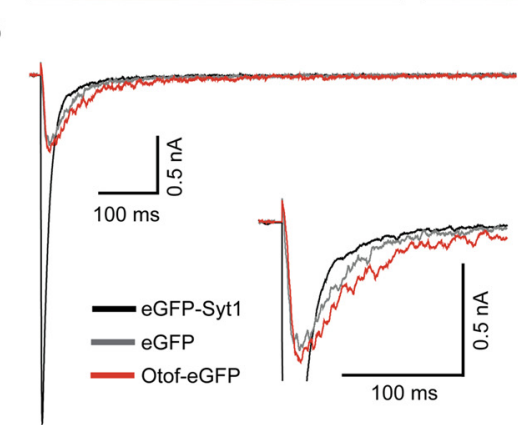

D

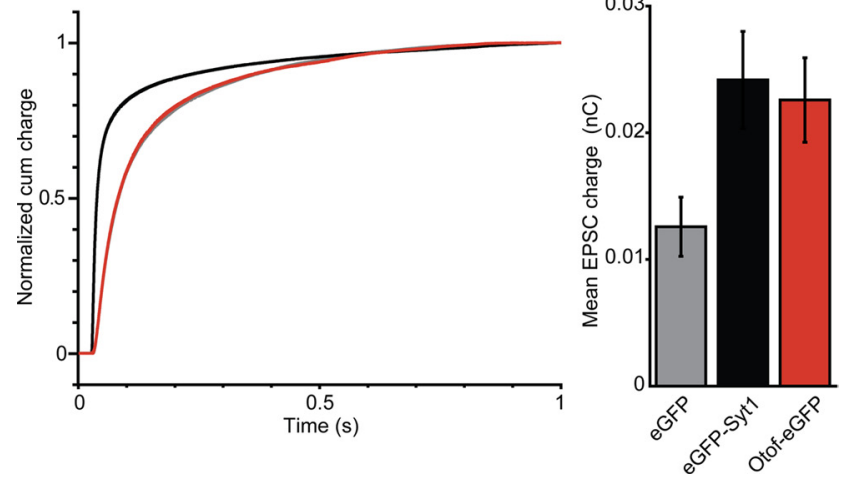

Figure 6. Otoferlin overexpression does not rescue synchronous transmitter release in Syt $1^{-1-}$ neurons. $\boldsymbol{A}$, Immunostaining of wild-type autaptic hippocampal neurons transfected with semliki forest virus carrying CDNA for Otof-eGFP. Scale bar, $10 \mu \mathrm{m}$. Otoferlin immunolabeling appears juxtaposed to Vglut1-immunolabeled presynaptic terminals. $\boldsymbol{B}$, Average EPSCs of Syt $1^{-/-}$neurons (10-15 DIV , $n=25$ each) that were kept as autaptic neuronal cultures for 10-15 d and transfected $12 \mathrm{~h}$ before recordings with a semliki forest virus encoding for eGFP-Syt1 (black), eGFP (gray), or Otof-eGFP (red). C, Quantification of mean EPSC amplitudes from B. D, Normalized EPSC integrals over time reveal a fast postsynaptic current for Syt $1^{-/-}$neurons that had been transfected with eGFP-Syt1 (black) but not for Syt1 ${ }^{-/-}$neurons expressing 0tof-eGFP (red) or eGFP alone (gray). $\boldsymbol{E}_{\text {, }}$ Mean EPSC integral: the evoked postsynaptic charge was increased by overexpression of 0tof- eGFP or eGFP-Syt1, but not eGFP alone, in Syt1-deficient autaptic hippocampal neurons. Note that otoferlin overexpression increased the charge of the asynchronous component only.

patch clamped them at 6-8 DIV (Figs. $1 C, 3 D$ ). Just as in nontransfected cultures of Otof ${ }^{-/-}$organs of Corti, exocytosis was nearly abolished in Syt1-overexpressing Otof ${ }^{-1-}$ IHCs (Fig. 3D). In summary, neither acute nor chronic ectopic expression of Syt1 restores $\mathrm{Ca}^{2+}$-triggered exocytosis in Otof ${ }^{-/-}$IHCs.

\section{Testing Syt1 function and analyzing Syt isoform expression in IHCs}

Although the absence of Syt1, Syt2, and Syt 3 was reported previously for guinea pig IHCs (Safieddine and Wenthold, 1999), a recent study claimed that Syt1 and Syt4 (potentially in combination with Syt2) function as $\mathrm{Ca}^{2+}$ sensors for exocytosis in IHCs of immature and mature mice, respectively (Johnson et al., 2010). In another study, a role for Syt 1 in immature hair cells was reported, together with the expression of both Syt1 and Syt2 in immature hair cells up to P8 (Beurg et al., 2010). Here, we tested the expression of Syt 1 and Syt 2 in IHCs by immunolabeling with isoform-specific antibodies. We found a very weak staining for Syt1 in the cytosol but not in the basolateral membrane at P3 (Fig. 4A, left). At later developmental stages (P9 or P19), we did not detect Syt1 protein, whereas Syt1 immunofluorescence was always observed in efferent presynaptic olivocochlear terminals underneath the IHCs serving as an intrinsic positive control of the Syt1 immunolabeling. We detected a weak cytosolic Syt 2 immunoreactivity in mouse IHCs at P3 and P9 but not after the onset of hearing (P19) (Fig. 4A, right). We then probed the expression of Syt isoforms 1-15 in rat IHCs by single-cell real-time PCR at P12 (Fig. 4E). Consistent with our immunohistochemistry in mice, Syt 1 mRNA was absent from rat IHCs. Also, we did not detect Syt4 mRNA in any P12 IHC and in only 2 of 18 IHCs at P14 (data not shown). However, mRNA of some other isoforms were detected, among them Syt2, the putative $\mathrm{Ca}^{2+}$-sensor of transmitter release at the calyx of Held synapse (Sun et al., 2007). We found Syt 2 mRNA in $80 \%$ of the IHCs at P12 (Fig. 4 E) but only in 7 of 18 IHCs at P14-P16 (data not shown).

Next, we studied exocytosis in IHCs of mice lacking Sytl using membrane capacitance measurements. Because Syt1 $1^{-/-}$mice die at birth, we performed the measurements in cultured organs of Corti of newborn mice after 6 DIV. Depolarization-evoked $\mathrm{Ca}^{2+}$ currents and exocytic membrane capacitance $\left(\Delta C_{\mathrm{m}}\right)$ for up to $200-\mathrm{ms}$ long depolarizations were unaltered in $S y t 1^{-/-}$IHCs, indicating that the absence of Syt 1 does not impair $\mathrm{Ca}^{2+}$-triggered fusion at the immature IHC synapse (Fig. $4 B-D$ ).

\section{Testing targeting and function of otoferlin in adrenal chromaffin cells}

Adrenal chromaffin cells represent an established model system of $\mathrm{Ca}^{2+}$ regulated exocytosis (Rettig and Neher, 2002). Chromaffin cells release epinephrine from large dense-core vesicles (chromaffin granules) during depolarization or flash photolysis of caged $\mathrm{Ca}^{2+}$ and use a set of synaptic proteins that primarily overlaps with the exocytic machinery of neuronal synapses. For example, Syt 1 is required for exocytosis of the readily releasable pool (RRP) in chromaffin cells (Voets et al., 2001), which is compatible with a $\mathrm{Ca}^{2+}$ sensor function of Syt1 for synchronous exocytosis. Therefore, it seemed sensible to test for potential effects of ectopic otoferlin expression in chromaffin cells. We transfected bovine chromaffin cells with a semliki forest virus encoding otoferlin-eGFP cDNA and analyzed by TIRFM whether otoferlin is targeted to chromaffin granules. The decaying evanescent field spatially restricted excitation of fluorophores to an $\sim 300 \mathrm{~nm}$ thin basal layer of the glass-attached chromaffin cell in our setup. We readily observed diffraction limited fluorescent objects moving in and out the evanescent field in which they stayed for different amounts of time (Fig. $5 A$ ), indicating that Otof-eGFP is, indeed, targeted to chromaffin granules that visited the near-membrane cytosol. We then performed whole-cell membrane capacitance $\left(C_{\mathrm{m}}\right)$ measurements to monitor exocytosis in response to flash photolysis of caged $\mathrm{Ca}^{2+}$. The flashinduced exocytic burst was analyzed using double-exponential fitting to the $C_{\mathrm{m}}$ traces over a period of $300 \mathrm{~ms}$. Fast (RRP) and slow (slowly releasable pool) components of the exocytic burst were maintained (Fig. $5 B$ ) with comparable kinetics $\left[\tau_{\text {fast }}(\right.$ Otofoverexpressing), $11.88 \pm 1.37 \mathrm{~ms}$ vs $\tau_{\text {fast }}$ (control), $13.39 \pm 1.23 \mathrm{~ms}$; $\tau_{\text {slow }}\left(\right.$ Otof-overexpressing), $242.25 \pm 24.16 \mathrm{~ms}$ vs $\tau_{\text {slow }}$ (control), $235.51 \pm 29.55 \mathrm{~ms}]$ and amplitudes $\left[A_{\text {fast }}\right.$ (Otof-overexpressing), $173.2 \pm 34.69 \mathrm{fF}$ vs $A_{\text {fast }}$ (control), $203.42 \pm 29.65 \mathrm{fF} ; A_{\text {slow }}$ (Otofoverexpressing), $321.02 \pm 48.54 \mathrm{fF}$ vs $A_{\text {slow }}$ (control), $270.95 \pm$ 

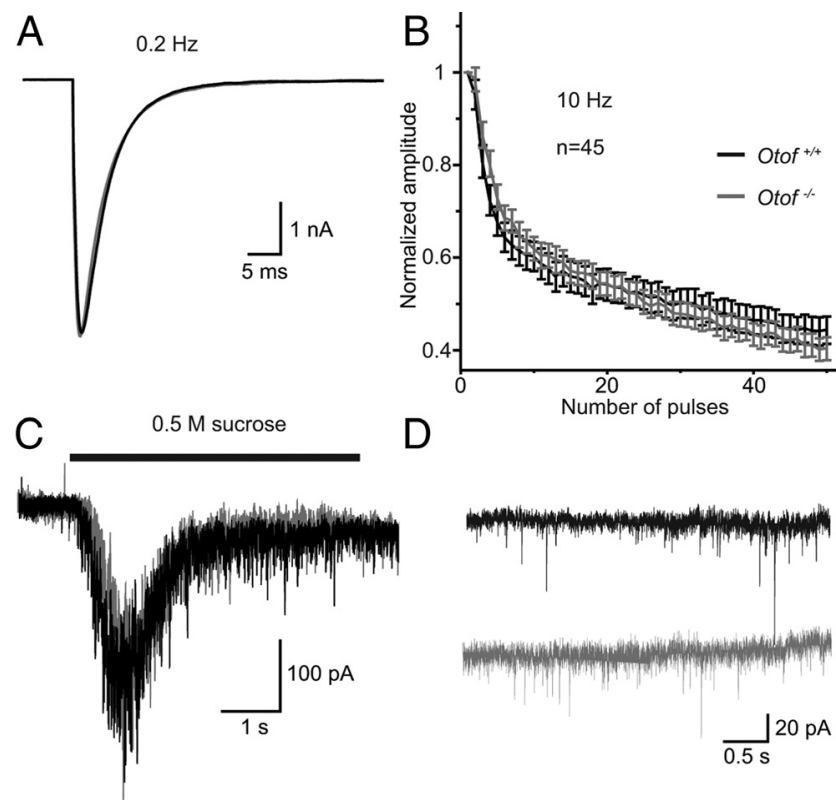

D

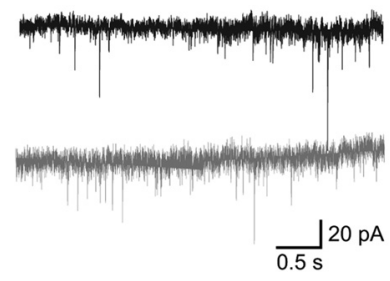

Figure 7. Exocytosis in Otof ${ }^{-/-}$hippocampal neurons. $A$, Representative EPSC traces from Otof $^{+/+}$(black) and $\mathrm{Otof}^{-/-}$(gray) autaptic hippocampal neurons at $10-15$ DIV, elicited by depolarizations to $0 \mathrm{mV}$ for $2 \mathrm{~ms}$ at $0.2 \mathrm{~Hz}$. B, Mean normalized amplitudes of EPSCs during a train of action potentials at $10 \mathrm{~Hz}$ from 0 tof ${ }^{+/+}$and Otof ${ }^{-/-}$hippocampal neurons. $C$, Representative traces showing the release of the RRP induced by application of $0.5 \mathrm{~m}$ sucrose. $\boldsymbol{D}$, Representative traces of mEPSCs in the presence of $300 \mathrm{~nm}$ TTX at $-70 \mathrm{mV}$. The frequency and the amplitude of $\mathrm{mEPSC}$ was unchanged in $\mathrm{Otof}^{-1-}$ neurons.

$28.03 \mathrm{fF}$ ] in transfected cells expressing otoferlin versus in nontransfected cells (same postflash $\left[\mathrm{Ca}^{2+}\right]_{\mathrm{i}}$ : Otofoverexpressing $(n=20), 15.67 \pm 0.69 \mu \mathrm{M}$ vs control $(n=20)$, $15.64 \pm 0.61 \mu \mathrm{M})$. Finally, we probed the potential of otoferlin overexpression to restore the synchronous exocytosis in Syt1-deficient mouse chromaffin cells. Syt1 deficiency specifically abolishes the fast component of the exocytic burst (Voets et al., 2001), which remained absent despite overexpression of otoferlin (Fig. 5C). Therefore, otoferlin seems incapable of functionally replacing Syt1 in chromaffin cell exocytosis.

\section{Testing the function of overexpressed otoferlin in Syt1-deficient hippocampal neurons}

Next, we expressed Otof-eGFP in hippocampal neurons of Syt $1^{-/-}$mice using the same semliki forest virus as used for chromaffin cells. Expression was confirmed by eGFP fluorescence during the recordings and on fixed cells by immunofluorescence using an anti-otoferlin antibody (Fig. 6A). Using otoferlin immunolabeling in cultured nontransfected hippocampal neurons, we did not detect immunofluorescence above that found in Otof ${ }^{-/-}$neurons (data not shown). During virus transduction to induce overexpression of otoferlin, costaining with the presynaptic protein Vglut1 showed a spot-like distribution for both antigens, but otoferlin immunolabeling appeared juxtaposed to the presynaptic boutons. We did not observe rescue of synchronous synaptic transmission in Syt1 ${ }^{-/-}$neurons overexpressing OtofeGFP, whereas it was restored by semliki forest virus-mediated expression of eGFP-Syt1 (Fig. 6B-D). However, there was an increase in asynchronous release in otoferlin-overexpressing Syt $1^{-/-}$neurons (Fig. $6 \mathrm{~B}$ ), leading to a larger total excitatory postsynaptic current (EPSC) charge in otoferlin-overexpressing Syt1 $1^{-1-}$ neurons compared with GFP-transfected neurons (Fig. $6 E)$. Furthermore, we found the amplitude of miniature EPSCs
(mEPSCs) to be slightly higher in otoferlin-overexpressing Syt1 ${ }^{-/-}$neurons $[25.93 \pm 2.24 \mathrm{pA}(n=25)$ compared with $18.87 \pm 1.06 \mathrm{pA}(n=17)$ in Syt1-transduced neurons], such that an increase in the number of postsynaptic AMPA receptors might have contributed to the larger EPSC charge.

\section{Functional analysis of otoferlin-deficient hippocampal neurons}

We next studied spontaneous and evoked exocytosis in Otof ${ }^{-/-}$autaptic hippocampal neurons to test for a potential role of endogenous otoferlin that might have escaped detection in our immunohistochemistry (Fig. 7). No difference was detected in EPSC amplitude, EPSC charge (Fig. 7A), RRP charge (measured during application of $0.5 \mathrm{M}$ sucrose) (Fig. 7C) or vesicular release probability $P_{\mathrm{vr}}$ (calculated as EPSC charge divided by RRP charge) between Otof ${ }^{+/+}$and Otof ${ }^{-/-}$hippocampal neurons. Furthermore, mEPSC amplitude or mEPSC frequency were unchanged between hippocampal neurons of the two genotypes (Fig. 7D). Thus, at least under these in vitro conditions, lack of otoferlin does not affect presynaptic function in hippocampal neurons.

\section{Discussion}

In this study, we tested for functional equivalence of Syt 1 and the hair cell $\mathrm{C}_{2}$ domain protein otoferlin. Despite a similar behavior of both proteins in biochemical experiments (Johnson and Chapman, 2010), we found that expression of Syt1 in IHCs cannot restore hair cell exocytosis in mice lacking otoferlin. Likewise, overexpression of otoferlin in chromaffin cells or hippocampal neurons did not rescue synchronous synaptic transmission in mice lacking Syt1. Although future site-directed mutagenesis studies need to scrutinize the putative $\mathrm{Ca}^{2+}$ sensor function of otoferlin in synaptic vesicle fusion in IHCs, our study demonstrates that it cannot simply be replaced by Syt1. Different from many other systems, cochlear hair cells have rarely if ever been used for exploring molecular structure-function relationships by viral gene transfer. This study demonstrated efficient in vitro and in vivo transduction procedures and revealed normal presynaptic properties of wild-type hair cells expressing the transgenes 5 weeks after transduction, paving the way for future site-directed mutagenesis studies of synaptic proteins in hair cells.

\section{Block of exocytosis in Otof ${ }^{-/-}$IHCs despite expression of Syt 2 and Syt 1}

The identity of the $\mathrm{Ca}^{2+}$ sensor(s) of hair cell exocytosis is the subject of current controversy. Our analysis of synaptotagmin expression in IHCs supports the conclusion of Safieddine and Wenthold (1999) and Beurg et al. (2010) that Syt1, Syt2, and Syt3 are absent in mature IHCs. The transient expression of Syt 2 seems not to be critical for exocytosis in immature IHCs (Beurg et al., 2010) and does not enable exocytosis in Otof ${ }^{-/-}$IHCs, which is nearly abolished from P4 onward (Roux et al., 2006; Beurg et al., 2010; this study). The lack of Syt 4 mRNA from P12 rat IHCs contrasts with a recent study on the role of Syt 4 in mouse IHCs (Johnson et al., 2010) that suggested that Syt4 serves as the $\mathrm{Ca}^{2+}$ sensor of exocytosis in mature mouse IHCs, potentially together with Syt2, questioning the hypothesis that otoferlin acts as the specialized $\mathrm{Ca}^{2+}$ sensor of exocytosis in IHCs. However, not only could we hardly detect Syt 4 mRNA in single hair cells, accumulating biochemical evidence also points toward a Syt1-like function of otoferlin (Johnson and Chapman, 2010). Our demonstration that the canonical $\mathrm{Ca}^{2+}$ sensor Syt 1 cannot rescue exocytosis in otoferlin-deficient IHCs seemingly argues against a $\mathrm{Ca}^{2+}$ sensing function of otoferlin in IHC transmitter release. 
However, the rescue approach may have failed despite a role of otoferlin as $\mathrm{Ca}^{2+}$ sensor of vesicle fusion in IHCs. First, upstream functions of otoferlin in IHCs, such as vesicle supply (Pangrsic et al., 2010), may not have been supported by Syt1. Second, absence of facilitating proteins such as complexins (Strenzke et al., 2009) or of Syt1 interaction partners could have precluded Syt1 functionality. The finding that ABRs could not be elicited in the Syt1AAV-1/2-injected Otof ${ }^{-1-}$ ears was most likely related to the remaining block of IHC exocytosis and not caused by too few transduced IHCs. If the $70 \%$ of the apical IHCs that expressed Syt1 were releasing transmitter in response, we would expect some ABR at least for low sound frequency stimulation because the ABR amplitude declines nearly linearly when the numbers of IHCs and spiral ganglion neurons are reduced by carboplatin application to the cochlea of chinchillas (Ding et al., 1999).

In the case of the mirror experiment, the overexpression of otoferlin in Syt1 ${ }^{-/-}$hippocampal neurons, we cannot exclude that failure to rescue synchronous vesicle release in hippocampal neurons might be attributable to mistargeting of overexpressed otoferlin, because it seems not to be primarily targeted to Vglut1 immunolabeled presynapses. In contrast, in chromaffin cells, proper targeting of otoferlin was indicated by labeling of the granules and still we observed a failure to rescue fast exocytosis. However, the C-terminal fusion to eGFP might have impaired the function of otoferlin, although the fluorophore is tagged to the intravesicular site of the protein that did not interfere with function in the case of Syt1 (Han et al., 2005). For both Syt1 ${ }^{-/-}$ chromaffin cells and hippocampal neurons, failure of rescue by otoferlin may have resulted from lack of otoferlin-interacting proteins required for exocytosis in both cell types or for presynaptic targeting in the case of hippocampal neurons.

\section{Auditory function after AAV-mediated gene transfer to the embryonic ear}

Gene transfer into mature cochlear hair cells has remained challenging (for review, see Brigande and Heller, 2009; Luebke et al., 2009; Wei and Yamoah, 2009). Here we demonstrate efficient viral transgene expression in IHCs and OHCs in vitro and in vivo using an AAV-1/2 vector carrying our gene of interest under the control of a CMV enhanced $\beta$-actin promoter. Wild-type IHCs transfected by transuterine injection of $\mathrm{AAV}-1 / 2$ presented mature stereocilliar bundle and cell body morphologies and intact $\mathrm{Ca}^{2+}$ currents and exocytosis in the fourth postnatal week. Together with the normal ABR recordings in mice up to 5 weeks of age misexpressing eGFP in IHCs, OHCs, and spiral ganglion neurons, these data suggest that the AAV-1/2 vector may be a suitable tool for therapeutic gene delivery to IHCs. We found increased ABR thresholds in the first set of Syt1-AAV-1/2-injected ears, which showed higher transfection rates in the middle and the basal parts of the cochlea than seen in the second set. We cannot exclude the possibility that ectopic Syt1 expression in hair cells causes auditory dysfunction but think that our patch-clamp data from the first set of injected ears and the near-normal auditory systems physiology in the second set of Syt1-AAV-1/2injected ears argue against it. Clearly, rescue experiments will be most conclusive at the level of auditory population responses such as ABRs, if (1) little degeneration has occurred, (2) transduction is efficient, and (3) the hearing loss of the non-rescued mutant is severe and the background strain shows good hearing. Unfortunately, the coding sequences of several deafness genes, including Otof, exceed the packaging capacity of AAV vectors, underlining the need to identify viral vectors with significantly larger capacities.

\section{Notes}

Supplemental material for this article is available at http:// www.innerearlab.uni-goettingen.de/materials.html. The movie shows TIRFM from otoferlin-eGFP-transfected chromaffin cells, indicating the otoferlin is targeted to chromaffin granules. This material has not been peer reviewed.

\section{References}

Bedrosian JC, Gratton MA, Brigande JV, Tang W, Landau J, Bennett J (2006) In vivo delivery of recombinant viruses to the fetal murine cochlea: transduction characteristics and long-term effects on auditory function. Mol Ther 14:328-335.

Berglund P, Sjöberg M, Garoff H, Atkins GJ, Sheahan BJ, Liljeström P (1993) Semliki forest virus expression system: production of conditionally infectious recombinant particles. Biotechnology (N Y) 11:916-920.

Beurg M, Michalski N, Safieddine S, Bouleau Y, Schneggenburger R, Chapman ER, Petit C, Dulon D (2010) Control of exocytosis by synaptotagmins and otoferlin in auditory hair cells. J Neurosci 30:13281-13290.

Beutner D, Voets T, Neher E, Moser T (2001) Calcium dependence of exocytosis and endocytosis at the cochlear inner hair cell afferent synapse. Neuron 29:681-690.

Brigande JV, Heller S (2009) Quo vadis, hair cell regeneration? Nat Neurosci 12:679-685.

Brigande JV, Gubbels SP, Woessner DW, Jungwirth JJ, Bresee CS (2009) Electroporation-mediated gene transfer to the developing mouse inner ear. Methods Mol Biol 493:125-139.

Chieregatti E, Witkin JW, Baldini G (2002) SNAP-25 and synaptotagmin 1 function in $\mathrm{Ca}^{2+}$-dependent reversible docking of granules to the plasma membrane. Traffic 3:496-511.

Cho W, Stahelin RV (2005) Membrane-protein interactions in cell signaling and membrane trafficking. Annu Rev Biophys Biomol Struct 34:119-151.

de Wit H, Walter AM, Milosevic I, Gulyás-Kovács A, Riedel D, Sørensen JB, Verhage M (2009) Synaptotagmin-1 docks secretory vesicles to syntaxin-1/ SNAP-25 acceptor complexes. Cell 138:935-946.

Ding DL, Wang J, Salvi R, Henderson D, Hu BH, McFadden SL, Mueller M (1999) Selective loss of inner hair cells and type-I ganglion neurons in carboplatin-treated chinchillas. Mechanisms of damage and protection. Ann N Y Acad Sci 884:152-170.

Gubbels SP, Woessner DW, Mitchell JC, Ricci AJ, Brigande JV (2008) Functional auditory hair cells produced in the mammalian cochlea by in utero gene transfer. Nature 455:537-541.

Han W, Rhee JS, Maximov A, Lin W, Hammer RE, Rosenmund C, Südhof TC (2005) C-terminal ECFP fusion impairs synaptotagmin 1 function: crowding out synaptotagmin 1. J Biol Chem 280:5089-5100.

Heidrych P, Zimmermann U, Kuhn S, Franz C, Engel J, Duncker SV, Hirt B, Pusch CM, Ruth P, Pfister M, Marcotti W, Blin N, Knipper M (2009) Otoferlin interacts with myosin VI: implications for maintenance of the basolateral synaptic structure of the inner hair cell. Hum Mol Genet 18:2779-2790.

Holmes TJ, Liu YH (1989) Richardson-Lucy/maximum likelihood image restoration algorithm for fluorescence microscopy: further testing. Appl Opt 28:4930-4938.

Jockusch WJ, Speidel D, Sigler A, Sørensen JB, Varoqueaux F, Rhee JS, Brose N (2007) CAPS-1 and CAPS-2 are essential synaptic vesicle priming proteins. Cell 131:796-808.

Johnson CP, Chapman ER (2010) Otoferlin is a calcium sensor that directly regulates SNARE-mediated membrane fusion. J Cell Biol 191:187-197.

Johnson SL, Franz C, Kuhn S, Furness DN, Rüttiger L, Münkner S, Rivolta MN, Seward EP, Herschman HR, Engel J, Knipper M, Marcotti W (2010) Synaptotagmin IV determines the linear $\mathrm{Ca}^{2+}$ dependence of vesicle fusion at auditory ribbon synapses. Nat Neurosci 13:45-52.

Kerr AM, Reisinger E, Jonas P (2008) Differential dependence of phasic transmitter release on synaptotagmin 1 at GABAergic and glutamatergic hippocampal synapses. Proc Natl Acad Sci U S A 105:15581-15586.

Khimich D, Nouvian R, Pujol R, Tom Dieck S, Egner A, Gundelfinger ED, Moser T (2005) Hair cell synaptic ribbons are essential for synchronous auditory signalling. Nature 434:889-894.

Kügler S, Hahnewald R, Garrido M, Reiss J (2007) Long-term rescue of a lethal inherited disease by adeno-associated virus-mediated gene transfer in a mouse model of molybdenum-cofactor deficiency. Am J Hum Genet 80:291-297. 
Luebke AE, Rova C, Von Doersten PG, Poulsen DJ (2009) Adenoviral and $\mathrm{AAV}$-mediated gene transfer to the inner ear: role of serotype, promoter, and viral load on in vivo and in vitro infection efficiencies. Adv Otorhinolaryngol 66:87-98.

Martens S, McMahon HT (2008) Mechanisms of membrane fusion: disparate players and common principles. Nat Rev Mol Cell Biol 9:543-556.

McNeil PL, Kirchhausen T (2005) An emergency response team for membrane repair. Nat Rev Mol Cell Biol 6:499-505.

Moser T, Beutner D (2000) Kinetics of exocytosis and endocytosis at the cochlear inner hair cell afferent synapse of the mouse. Proc Natl Acad Sci U S A 97:883-888.

Neef J, Gehrt A, Bulankina AV, Meyer AC, Riedel D, Gregg RG, Strenzke N, Moser T (2009) The $\mathrm{Ca}^{2+}$ channel subunit $\beta 2$ regulates $\mathrm{Ca}^{2+}$ channel abundance and function in inner hair cells and is required for hearing. J Neurosci 29:10730-10740.

Nicholson-Tomishima K, Ryan TA (2004) Kinetic efficiency of endocytosis at mammalian CNS synapses requires synaptotagmin I. Proc Natl Acad Sci U S A 101:16648-16652.

Pangrsic T, Lasarow L, Reuter K, Takago H, Schwander M, Riedel D, Frank T, Tarantino LM, Bailey JS, Strenzke N, Brose N, Müller U, Reisinger E, Moser T (2010) Hearing requires otoferlin-dependent efficient replenishment of synaptic vesicles in hair cells. Nat Neurosci 13:869-876.

Ramakrishnan NA, Drescher MJ, Drescher DG (2009) Direct interaction of otoferlin with syntaxin 1A, SNAP-25, and the L-type voltage-gated calcium channel Cav1.3. J Biol Chem 284:1364-1372.

Rettig J, Neher E (2002) Emerging roles of presynaptic proteins in $\mathrm{Ca}^{2+}$. triggered exocytosis. Science 298:781-785.

Rizo J, Südhof TC (1998) C2-domains, structure and function of a universal $\mathrm{Ca}^{2+}$-binding domain. J Biol Chem 273:15879-15882.

Roux I, Safieddine S, Nouvian R, Grati M, Simmler MC, Bahloul A, Perfettini I, Le Gall M, Rostaing P, Hamard G, Triller A, Avan P, Moser T, Petit C (2006) Otoferlin, defective in a human deafness form, is essential for exocytosis at the auditory ribbon synapse. Cell 127:277-289.

Roux I, Hosie S, Johnson SL, Bahloul A, Cayet N, Nouaille S, Kros CJ, Petit C, Safieddine S (2009) Myosin VI is required for the proper maturation and function of inner hair cell ribbon synapses. Hum Mol Genet 18:4615-4628.

Safieddine S, Wenthold RJ (1999) SNARE complex at the ribbon synapses of cochlear hair cells: analysis of synaptic vesicle- and synaptic membraneassociated proteins. Eur J Neurosci 11:803-812.

Schwander M, Sczaniecka A, Grillet N, Bailey JS, Avenarius M, Najmabadi H, Steffy BM, Federe GC, Lagler EA, Banan R, Hice R, Grabowski-Boase L, Keithley EM, Ryan AF, Housley GD, Wiltshire T, Smith RJ, Tarantino LM, Müller U (2007) A forward genetics screen in mice identifies recessive deafness traits and reveals that pejvakin is essential for outer hair cell function. J Neurosci 27:2163-2175.

Smerdou C, Liljeström P (1999) Two-helper RNA system for production of recombinant Semliki forest virus particles. J Virol 73:1092-1098.

Smith C, Moser T, Xu T, Neher E (1998) Cytosolic $\mathrm{Ca}^{2+}$ acts by two separate pathways to modulate the supply of release-competent vesicles in chromaffin cells. Neuron 20:1243-1253.

Sørensen JB, Nagy G, Varoqueaux F, Nehring RB, Brose N, Wilson MC, Neher E (2003) Differential control of the releasable vesicle pools by SNAP-25 splice variants and SNAP-23. Cell 114:75-86.

Staudt T, Lang MC, Medda R, Engelhardt J, Hell SW (2007) 2,2'-thiodiethanol: a new water soluble mounting medium for high resolution optical microscopy. Microsc Res Tech 70:1-9.

Strenzke N, Chanda S, Kopp-Scheinpflug C, Khimich D, Reim K, Bulankina AV, Neef A, Wolf F, Brose N, Xu-Friedman MA, Moser T (2009) Complexin-I is required for high-fidelity transmission at the endbulb of held auditory synapse. J Neurosci 29:7991-8004.

Sun J, Pang ZP, Qin D, Fahim AT, Adachi R, Südhof TC (2007) A dual$\mathrm{Ca}^{2+}$-sensor model for neurotransmitter release in a central synapse. Nature 450:676-682.

Voets T, Moser T, Lund PE, Chow RH, Geppert M, Südhof TC, Neher E (2001) Intracellular calcium dependence of large dense-core vesicle exocytosis in the absence of synaptotagmin I. Proc Natl Acad Sci U S A 98:11680-11685.

Wei D, Yamoah EN (2009) Regeneration of the mammalian inner ear sensory epithelium. Curr Opin Otolaryngol Head Neck Surg 17:373-380.

Young SM Jr, Neher E (2009) Synaptotagmin has an essential function in synaptic vesicle positioning for synchronous release in addition to its role as a calcium sensor. Neuron 63:482-496.

Zhou Z, Neher E (1993) Mobile and immobile calcium buffers in bovine adrenal chromaffin cells. J Physiol 469:245-273. 